\title{
Comments on "Association of excessive mobile phone use during pregnancy with birth weight: an adjunct study in Kumamoto of Japan Environment and Children's Study"
}

\author{
Ghazal Mortazavi ${ }^{1}$, S.A.R. Mortazavi ${ }^{2}$ and S.M.J. Mortazavi ${ }^{1,3^{*}}$ (i) \\ See related research by Lu et al., https://environhealthprevmed.biomedcentral.com/articles/10.1186/s12199-017-0656-1
}

\begin{abstract}
We have read with interest the article by Lu et al. entitled "Association of excessive mobile phone use during pregnancy with birth weight: an adjunct study in Kumamoto of Japan Environment and Children's Study" published recently in the Environmental Health and Preventive Medicine. Although this paper addresses a very challenging issue, it has some shortcomings. Mortazavi et al. have previously studied the effects of ionizing and non-ionizing radiation on birth weight of newborns and found no statistical significant differences between the mean weight of newborns whose mothers had been exposed to electromagnetic fields (EMF) generated by mobile phones and those of non-exposed mothers. The study performed by Lu et al. cannot answer this very key question that whether ordinary use of mobile phone during pregnancy can lead to low birth weight. The origin of the controversy between the findings of these two studies and the shortcomings of the article by Lu et al. are discussed.
\end{abstract}

Keywords: Mobile phone use, Electromagnetic fields, Pregnancy, Birth weight

This letter is regarding the Environmental Health and Preventive Medicine article by Lu et al. entitled "Association of excessive mobile phone use during pregnancy with birth weight: an adjunct study in Kumamoto of Japan Environment and Children's Study" [1]. This paper claims that excessive mobile phone use during pregnancy may be a risk factor for lower birth weight "The mean infant birth weight was lower in the excessive use group than in the ordinary use group, and the frequency of infant emergency transport was significantly higher in the excessive use group than in the ordinary use group".

\footnotetext{
* Correspondence: s.m.javad.mortazavi@fccc.edu

${ }^{1}$ Ionizing and Non-ionizing Radiation Protection Research Center (INIRPRC),

Shiraz University of Medical Sciences, Shiraz, Iran

${ }^{3}$ Diagnostic Imaging Center, Fox Chase Cancer Center, Philadelphia, PA

19111, USA

Full list of author information is available at the end of the article
}

The study performed by Lu et al. has some major shortcomings. The effects of ionizing and non-ionizing radiation on birth weight of newborns have been previously studied by Mortazavi et al. These researchers in 2013 showed that there were no statistical significant differences between the mean weight of newborns whose mothers had been exposed to electromagnetic fields (EMF) generated by mobile phones, cordless phones, and cathode ray tubes (CRT) and those of non-exposed mothers [2]. In the study performed by Mortazavi et al., $52.75 \%$ had made use of cell phones during their pregnancy. The mean birth weight of newborns to mothers making use of cell phones was $3126.84 \pm 509.39 \mathrm{~g}$ and that of newborns to mothers not using cell phones was $3098.44 \pm 51.22 \mathrm{~g}$. This difference was not statistically significant. Moreover, $78.5 \%$ had never made use of home cordless phones during their pregnancy. The 
mean birth weight of newborns to these mothers was $3113.31 \pm 511.47 \mathrm{~g}$ and the mean birth weight of newborns to mothers who had used such phones during their pregnancy was $3101.32 \pm 505.07 \mathrm{~g}$. This difference was not statistically significant.

Finally, 84.5\% had never used CRT monitors during their pregnancy. The mean birth weight of newborns to such mothers was $3108.32 \pm 516.89 \mathrm{~g}$ and newborns to mothers using such devices was $3126.69 \pm 466.69 \mathrm{~g}$. Again, no statistically significant difference was found between these two groups.

In this light, our findings are not in line with those reported by $\mathrm{Lu}$ et al. Searching for the source of this discrepancy reveals that in the study performed by $\mathrm{Lu}$ et al., the mean birth weight of 415 ordinary users $(90.02 \%$ of the 461 study participants) is compared with that of 46 excessive users (9.98\% of the participants). In this light, this very challenging key question that whether ordinary use of mobile phone during pregnancy (the actual scenario for more than $90 \%$ of the mothers participated in this study) can lead to low birth weight, remains unanswered.

The 2nd shortcoming of this paper comes from this point that the 46 (9.98\%) excessive users in the study performed by Lu et al. were possibly among the people who more experience stress and anxiety due to problems such as turbulent marriage and stressful jobs. It is worth mentioning that positive associations between "high" compared to "low mobile phone use" and current stress, sleep disturbances, and symptoms of depression have been reported by Thomee et al. [3].

\section{Authors' response}

\section{Xi Lu, Masako Oda, Takashi Ohba, Hiroshi Mitsubuchi, Shota Masuda and Takahiko Katoh}

We thank the research group for their interest in our study titled "Association of excessive mobile phone use during pregnancy with birth weight: an adjunct study in Kumamoto of Japan Environment and Children's Study" as well as their highly relevant comments on our work. Please find below our responses on the points raised by the commenters:

1. Based on our title [1], our study aimed to determine the association between excessive mobile phone use and neonatal birth weight and infant health status. The purpose of this study does not include the study of the effects of the phone's electromagnetic fields on these two outcomes. Excessive mobile phone use is recognized as a consequential social problem; however, its effects on the fetus during pregnancy remain to be fully determined. Thus, we just focused on the differences in the neonatal birth weight and infant health status between mothers who were excessive mobile users and those who were normal mobile users.

Although the goal of our study is not to determine the effects of the electromagnetic fields on the two previously mentioned outcomes, we also checked the daily designated spot, power state during sleep, and location of the mobile phone when sleeping during pregnancy to prevent bias (Table 1). In terms of the designated spot for mobile phone, the excessive mobile use group more frequently placed the mobile phone in the trouser or shirt pocket than the ordinary mobile use group $(P<0.05)$. However, no statistically significant differences in the power state and location of the mobile phone were observed between the two groups. Additionally, as pointed out in our discussion, "We also found that the excessive use group preferred to place the mobile phone in the trouser or shirt pocket, indicating that the excessive use group preferred to have the mobile phone in an easily accessible location." Therefore, our finding suggests that excessive mobile phone use during pregnancy may be a risk factor for low neonatal birth weight. This finding is not against with that of Mortazavi et al. [2]. However, one key issue must be raised in the study of Mortazavi et al., that is, the exclusion of mothers with addiction from the data analysis (no further detail on the definition of addiction was provided) [2]. This exclusion may be the reason for the absence of any statistically significant difference in the newborns' birth weights between mothers who were exposed to radiation and those who were not.

2. As previously mentioned, the objective of our study was to determine the differences in the neonatal birth weight and infant health status between mothers who were excessive mobile phone users and those who were normal mobile phone users. Hence, our study sample included mothers who were "excessive mobile phone users." Some studies already reported that excessive mobile phone use was correlated with sleeping problems, stress, depression, and other mental health issues [4-6]. These findings were also reflected in our discussion: "Our study suggests that excessive mobile phone use during pregnancy may cause mental problems, such as anxiety and depression, and health problems, such as sleep problems and sleeplessness."

\section{Abbreviations \\ CRT: Cathode ray tube; EMF: Electromagnetic fields}

\section{Acknowledgements}

We are grateful for the kind cooperation of all students who helped us in this study.

Funding

Not applicable. 
Availability of data and materials

Not applicable.

\section{Authors' contributions}

All authors were involved in drafting the manuscript and revising it. All authors read and approved the final manuscript.

\section{Authors' information}

1. Ghazal Mortazavi is a dentist at INIRPRC, Shiraz University of Medical Sciences, Shiraz, Iran.

2. SAR Mortazavi is a Medical student at School of Medicine, Shiraz University of Medical Sciences, Shiraz, Iran.

3. SMJ Mortazavi is a visiting scientist at Diagnostic Imaging Center, Fox Chase Cancer Center, Philadelphia, PA 19111, USA.

\section{Ethics approval and consent to participate}

Not applicable.

\section{Consent for publication}

Not applicable.

\section{Competing interests}

The authors declare that they have no competing interests.

\section{Publisher's Note}

Springer Nature remains neutral with regard to jurisdictional claims in published maps and institutional affiliations.

\section{Author details}

${ }^{1}$ Ionizing and Non-ionizing Radiation Protection Research Center (INIRPRC), Shiraz University of Medical Sciences, Shiraz, Iran. ${ }^{2}$ Student Research Committee, School of Medicine, Shiraz University of Medical Sciences, Shiraz, Iran. ${ }^{3}$ Diagnostic Imaging Center, Fox Chase Cancer Center, Philadelphia, PA 19111, USA.

Received: 7 July 2017 Accepted: 7 September 2017

Published online: 16 September 2017

\section{References}

1. Lu X, Oda M, Ohba T, Mitsubuchi H, Masuda S, Katoh T. Association of excessive mobile phone use during pregnancy with birth weight: an adjunct study in Kumamoto of Japan Environment and Children's Study Environ Health Prev Med. 2017;22(1):52.

2. Mortazavi SM, Shirazi KR, Mortazavi G. The study of the effects of ionizing and non-ionizing radiations on birth weight of newborns to exposed mothers. J Nat Sci Biol Med. 2013;4(1):213-7. PubMed PMID: 23633865. Pubmed Central PMCID: PMC3633280. Epub 2013/05/02. eng

3. Thomée S, Härenstam A, Hagberg M. Mobile phone use and stress, sleep disturbances, and symptoms of depression among young adults--a prospective cohort study. BMC Public Health. 2011;11:66. PubMed PMID: PMC3042390

4. Salehan $M$, Negahban A. Social networking on smartphones: when mobile phones become addictive. Comput Human Berav. 2013;29:2632-9.

5. Rosen L, Carrier LM, Miller A, Rokkum J. Ruiz. Sleeping with technology: cognitive, affective, and technology usage predictors of sleep problems among college students. Sleep Health. 2016;2:49-56.

6. Lu X, Chen Z, Uji M, Nagata T, Katoh T, Kitamura T. Use of mobile phone text message and personality among Japanese university students. Psychv Behav Sci. 2013:2:192-5.

Submit your next manuscript to BioMed Central and we will help you at every step:

- We accept pre-submission inquiries

- Our selector tool helps you to find the most relevant journal

- We provide round the clock customer support

- Convenient online submission

- Thorough peer review

- Inclusion in PubMed and all major indexing services

- Maximum visibility for your research

Submit your manuscript at www.biomedcentral.com/submit
Biomed Central 